\title{
Simultaneous determination of amino acids and carbohydrates by anion-exchange chromatography with integrated pulsed amperometric detection
}

\author{
Hong $\mathrm{Yu}^{\mathrm{a}, \mathrm{c}}$, Yong-Sheng Ding ${ }^{\mathrm{a}}$, Shi-Fen Mou ${ }^{\mathrm{a}, *}$, Petr Jandik ${ }^{\mathrm{b}}$, Jun Cheng ${ }^{\mathrm{b}}$ \\ ${ }^{a}$ Research Center for Eco-Environmental Sciences, Academia Sinica, PO Box 2871, Beijing 100085, PR China \\ ${ }^{\mathrm{b}}$ Dionex Corporation, Sunnyvale, CA 94086, USA \\ ${ }^{\mathrm{c}}$ Department of Chemistry, Harbin Normal University, Harbin 150080, PR China
}

Received 1 February 2002; received in revised form 23 May 2002; accepted 23 May 2002

\begin{abstract}
A direct, sensitive, simple and practical method for simultaneous determination of amino acids and carbohydrates by anion-exchange chromatography with integrated pulsed amperometric detection was developed. The retention behavior of amino acids and carbohydrates on the anion-exchange column and the detection of amino acids and carbohydrates at different integrated pulsed amperometric detection waveforms were investigated. The optimized gradient eluent conditions for analysis of 17 amino acids and nine carbohydrates were obtained. Separation time was $100 \mathrm{~min}$. Detection limits for amino acids and carbohydrates were 5.2-207.1 $\mathrm{n} M$ under injection volume of $25 \mu l$. The RSDs of peak area were 1.2-3.3\%. The calibration graphs of peak area for the analytes were linear over about three orders of magnitude with a correlation coefficient of $0.9950-0.9999$. The method was applied to determine amino acids and carbohydrates in a liquid condiment with satisfactory results.
\end{abstract}

(C) 2002 Elsevier Science B.V. All rights reserved.

Keywords: Amino acids; Carbohydrates

\section{Introduction}

The determination of amino acids and carbohydrates is important in life science, food science, medical science, and agriculture science. At present, the methods for separating and determining amino acids mainly include cation-exchange chromatography with post-column derivatization and spectro-

\footnotetext{
*Corresponding author. Tel.: +86-10-6284-9239; fax: +86-106284-9239.

E-mail address: shifenm@mail.rcees.ac.cn (S.-F. Mou).
}

photometric detection [1], reversed-phase high-performance liquid chromatography with pre-column derivatization and spectrophotometric detection [2], and capillary electrophoresis [3]. The methods for separating and determining carbohydrates mainly include gas chromatography with derivatization [4], high-performance liquid chromatography with refractive index detection or derivative spectrophotometric detection [5], high-performance anion-exchange chromatography with pulsed amperometric detection [6], and capillary electrophoresis [7]. When the above methods are used to determine amino acids 
and carbohydrates, derivatization is always employed and, generally, a method can only determine one kind of compound-amino acid or carbohydrate. However, in many cases, amino acids and carbohydrates coexist in a sample and both need to be determined. If direct and simultaneous determination of amino acids and carbohydrates is achieved, this will increase the efficiency of analysis. In 1999, Clarke et al. [8] developed an integrated amperometry waveform for the direct, sensitive detection of amino acids and amino sugars following anion-exchange chromatography. The method has been used to determine amino acids in samples of hydrolysate, carrot juice and cell culture [8-10].

This paper presents a direct, simultaneous determination of amino acids and carbohydrates by anion-exchange chromatography followed by integrated pulsed amperometric detection (IPAD). The retention behavior of amino acids and carbohydrates on an anion-exchange column and the detection of amino acids and carbohydrates with two different IPAD waveforms were investigated. Optimized gradient elution conditions for the analysis of 17 amino acids and nine carbohydrates were obtained. The new method was applied to determine amino acids and carbohydrates in a liquid condiment sample.

\section{Experimental}

\subsection{Apparatus}

All experiments were performed using a DX-600 ion chromatograph (Dionex, Sunnyvale, CA, USA). The ion chromatographic system consisted of a GS50 gradient pump with on-line degas, an AS50 autosampler, an AS50 thermal compartment containing a set of chromatographic columns, and an ED50 electrochemical detector equipped with a thin-layer type amperometric cell. The cell consisted of a gold electrode, $\mathrm{Ag} / \mathrm{AgCl}(3 \mathrm{M} \mathrm{KCl})$ reference electrode and titanium counter electrode consisting of the cell body. The electrochemical detection cell was also placed inside the AS50 thermal compartment for temperature control. The chromatographic system control, data acquisition and data analysis were performed using PeakNet 6.1 software.

\subsection{Chemicals}

Standard reference material amino acids (SRM 2389 NIST, Gaithersburg, MD, USA), D-glucose, D-fructose, D-arabinose, L-fucose, D-ribose, sucrose, lactose, raffinose, and maltose were used to prepare the standard solution. All standard carbohydrates (purity $\geq 95 \%$ ) and sodium azide were purchased from Sigma-Aldrich (St. Louis, MO, USA). The injected standard mixture solutions of amino acids and carbohydrates were made by diluting SRM 2389 and corresponding aliquots of single component stock solutions of carbohydrates with an aqueous diluent containing $20 \mathrm{mg} / 1$ sodium azide. The single component stock solutions of carbohydrates $(\sim 1.0$ $\mathrm{m} M$ ) were prepared by dissolving solid carbohydrates in $20 \mathrm{mg} / 1$ sodium azide diluent.

To prepare the gradient mobile phases, $18 \mathrm{M} \Omega$ water, sodium hydroxide (Beijing Chemical Factory, China), and anhydrous sodium acetate (Dionex) were used. Mobile phase I was $18 \mathrm{M} \Omega$ water vacuumfiltered through a $0.2-\mu \mathrm{m}$ nylon filter. Mobile phase II, a $250 \mathrm{~m} M$ sodium hydroxide solution, was prepared by diluting an aliquot of $50 \%$ sodium hydroxide, which was prepared by dissolving solid sodium hydroxide in $18 \mathrm{M} \Omega$ water. The resulting $50 \%$ solution was kept undisturbed for $24 \mathrm{~h}$ to allow the sodium carbonate to settle at the bottom prior to the last dilution step to $250 \mathrm{~m} M$. Mobile phase III, a $1 M$ sodium acetate solution, was prepared by dissolving an aliquot of anhydrous sodium acetate in $18 \mathrm{M} \Omega$ water and filtering the solution through a $0.2-\mu \mathrm{m}$ nylon filter. All three mobile phases were kept under nitrogen to prevent accumulation of atmospheric carbon dioxide.

\subsection{Chromatographic conditions}

The AminoPac PA 10 column set consisting of a guard column ( $50 \mathrm{~mm} \times 2 \mathrm{~mm}$ I.D.) and an analytical column ( $250 \mathrm{~mm} \times 2 \mathrm{~mm}$ I.D.) was used to separate amino acids and carbohydrates. Both columns were packed with an identical microporous, polymeric anion-exchange material. The total ion-exchange capacity of the analytical column was 60 mequiv. Gradient elution was performed at a flow-rate of 0.25 $\mathrm{ml} / \mathrm{min}$, with water, sodium hydroxide and sodium 
Table 1

Gradient condition for analyzing 17 amino acids and nine carbohydrates

\begin{tabular}{rllll}
\hline $\begin{array}{r}\text { Time } \\
(\mathrm{min})\end{array}$ & $\begin{array}{l}\text { Water } \\
(\%)\end{array}$ & $\begin{array}{l}250 \mathrm{~m} M \\
\mathrm{NaOH}(\%)\end{array}$ & $\begin{array}{l}1 M \mathrm{NaAc} \\
(\%)\end{array}$ & Curve $^{\mathrm{a}}$ \\
\hline 0.0 & 90 & 10 & & \\
2.0 & 90 & 10 & & 8 \\
5.0 & 85 & 15 & & 8 \\
11.0 & 70 & 30 & & 8 \\
13.0 & 65 & 35 & & 8 \\
15.0 & 60 & 40 & & 8 \\
18.0 & 50 & 50 & & 8 \\
20.0 & 30 & 70 & 5 & 8 \\
28.0 & 30 & 70 & 10 & 8 \\
28.1 & 25 & 70 & 20 & 8 \\
32.0 & 30 & 60 & 40 & 8 \\
35.0 & 30 & 50 & 50 & \\
40.0 & 20 & 40 & 50 & 5 \\
45.0 & 20 & 30 & & \\
65.0 & 20 & 30 & & \\
65.1 & 20 & 80 & & \\
67.1 & 20 & 80 & & \\
67.2 & 90 & 10 & 10 & \\
100.0 & 90 & 10 & & \\
\hline
\end{tabular}

${ }^{\text {a }}$ Shapes of gradient curves are defined in the GS 50 Gradient Pump Operator's Manual, pp. 37-38 (Dionex Document No. 031612 , Revision 2). Curve 5 is linear while curve 8 is one of the four available concave curves (6-9) with $20 \%$ change at $\sim 60 \%$ of a time segment and $70 \%$ change at $\sim 90 \%$ of the same programmed time segment.

acetate mobile phases using the ternary gradient method of Table 1. The integrated amperometry detection waveform is presented in Table 2. The temperature of the AS50 thermal compartment was maintained at $30{ }^{\circ} \mathrm{C}$. The sample injection volume was $25 \mu l$.

\section{Results and discussion}

\subsection{The separation of amino acids and carbohydrates with anion-exchange chromatography}

Because amino acids and carbohydrates can form anions under alkaline $\mathrm{pH}$ conditions, anion-exchange chromatography using sodium hydroxide and sodium acetate solutions as eluents is suitable for separating amino acids and carbohydrates. Fig. 1 shows the effect of the eluent concentration of sodium hy-
Table 2

Detection waveform for amino acids and carbohydrates

\begin{tabular}{rll}
\hline $\begin{array}{l}\text { Time } \\
(\mathrm{ms})\end{array}$ & $\begin{array}{l}\text { Potential }(\mathrm{V}) \mathrm{vs} . \\
\mathrm{Ag} / \mathrm{AgCl}(3 \mathrm{MCl})\end{array}$ & $\begin{array}{l}\text { Current } \\
\text { integration }\end{array}$ \\
\hline 0 & -0.20 & \\
40 & -0.20 & \\
50 & 0.00 & Begin \\
210 & 0.00 & \\
220 & 0.27 & \\
460 & 0.27 & \\
470 & 0.00 & \\
560 & 0.00 & \\
570 & -2.00 & \\
580 & -2.00 & \\
590 & 0.60 & \\
600 & -0.20 & \\
\hline
\end{tabular}

droxide on the separation of amino acids and carbohydrates. From Fig. 1, we can see that the retention time of amino acids (except for arginine) and carbohydrates decreased with increasing concentration of sodium hydroxide between 20 and $120 \mathrm{mM}$. Because

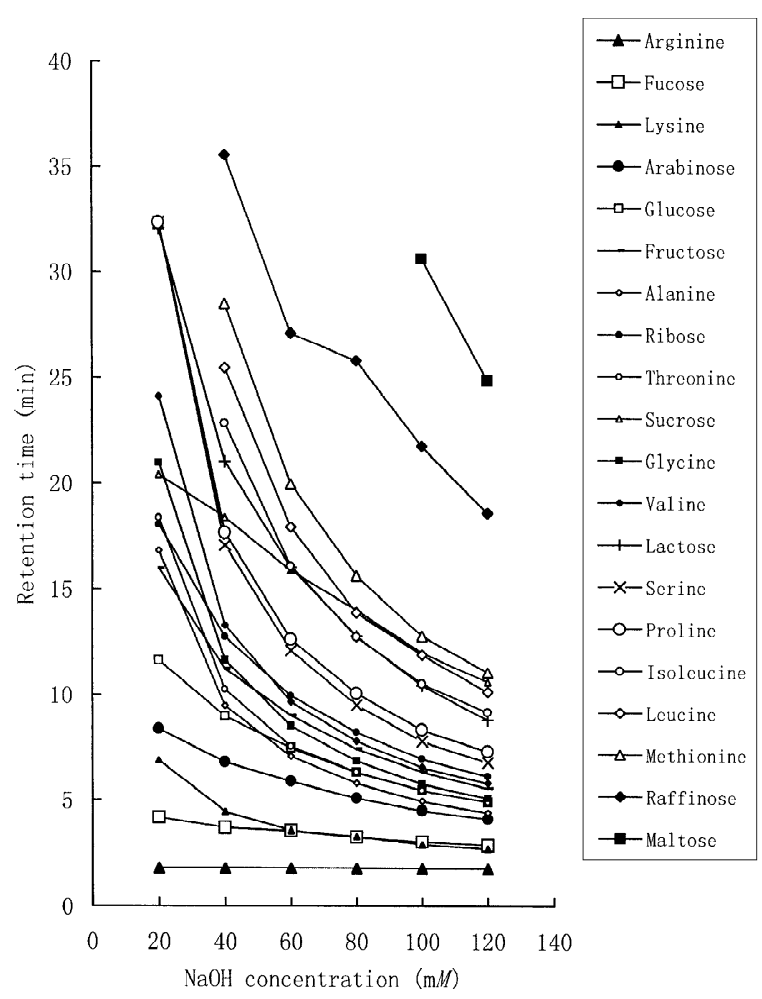

Fig. 1. The effect of sodium hydroxide concentration on the separation of amino acids and carbohydrates. 
of its lack of negative charge, even under high alkaline condition [10], the retention time of arginine is not affected by changes in the concentration of sodium hydroxide. For all amino acids (except for arginine), the decrease in the retention times is generally greater than that for carbohydrates. The reason for this phenomenon lies in the acidity of amino acids being stronger than that of carbohydrates. The difference in retention times is generally greater for strongly acidic analytes than for weakly acidic analytes when sodium hydroxide eluent concentration is varied in anion-exchange chromatography. The above differences can be used to improve separations between amino acids and carbohydrates.

If only sodium hydroxide solutions are used for the elution of strongly retained amino acids such as histidine, phenylalanine, glutamate, aspartate, cystine and tyrosine, those amino acids are not eluted from the column even at an eluent concentration as high as $200 \mathrm{~m} M$ of sodium hydroxide. The strongly retained amino acids can be eluted only by a suitably high concentration of a stronger eluent such as sodium

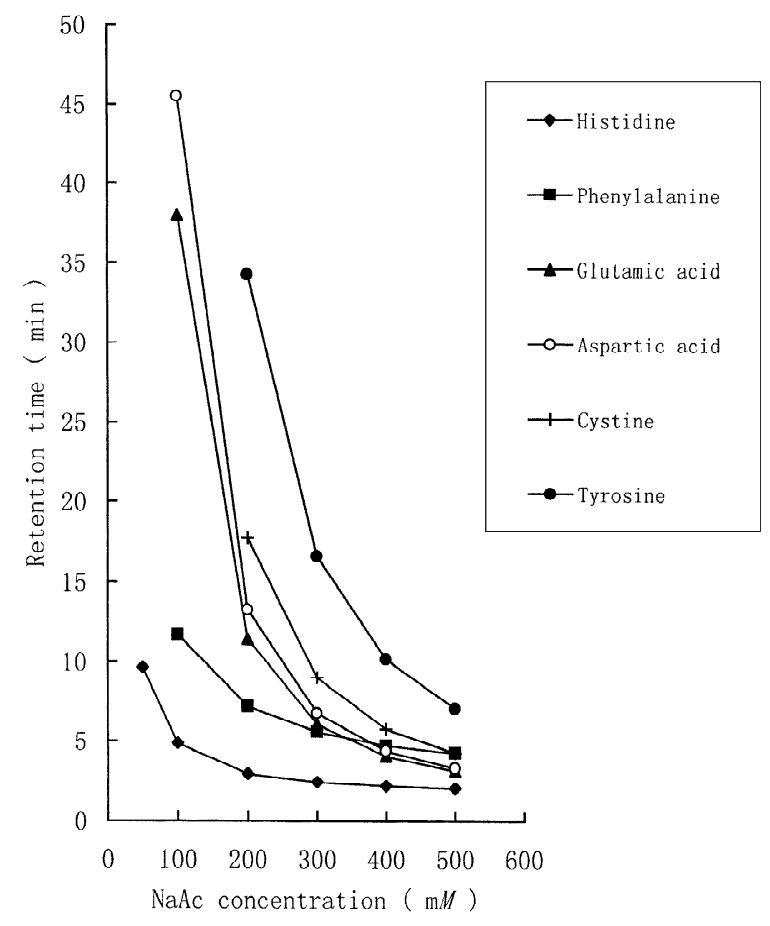

Fig. 2. The effect of sodium acetate concentration on the separation of amino acids. The sodium hydroxide concentration is held constant at $60 \mathrm{~m} M$. acetate. Fig. 2 illustrates the effect of the concentration of sodium acetate on the separation of strongly retained amino acids. From Fig. 2, we can see that the stronger concentration of sodium acetate produces a greater decrease in the retention time for the amino acids containing two carboxyl groups than for the amino acids containing only one carboxyl group. The above observations can be used to improve separations between dicarboxylic amino acids and mono-carboxylic amino acids.

From the above, it also follows that the anionexchange separations of amino acids and carbohydrates always require gradient elution methods employing both sodium hydroxide and sodium acetate. The optimized gradient conditions for separating 17 amino acids and nine carbohydrates are given in Table 1. A chromatogram obtained under these conditions is shown in Fig. 3.

\subsection{Integrated pulsed amperometric detection of amino acids and carbohydrates}

The amino group of amino acids and hydroxyl group of carbohydrates can be oxidized on the surface of a gold electrode, in strongly alkaline solution by applying a suitable potential. Both groups of compounds can be detected simultaneously with IPAD $[8,11,12]$. We investigated the response of amino acids and carbohydrates at different "sampling step" potentials (sampling step: the potential between 220 and $460 \mathrm{~ms}$ in Table 2). Table 3 gives the peak areas of amino acids and carbohydrates at several different sampling step potentials in the range of -0.03 to $0.27 \mathrm{~V}$ (vs. $\mathrm{Ag} / \mathrm{AgCl}, 3 \mathrm{M} \mathrm{KCl}$ ). We have found that the step potentials higher than 0.27 $\mathrm{V}$ are not suitable for a gold electrode employed for amino acid detection in alkaline solutions. Too high values of the step potentials will produce an excessive gold oxide layer that cannot be completely reduced to gold during the cleaning step (Tables 2 and $4 ; 570 \mathrm{~ms},-2 \mathrm{~V}$ ). This leads to a slow passivation of the gold electrode surface resulting in a gradual decrease of detection response.

From Table 3, we can see that the peak areas of all amino acids, except of those carrying a hydroxyl group, show a marked decrease with decreased value of the sampling step potential. On the other hand, the peak areas of carbohydrates and hydroxyl amino 


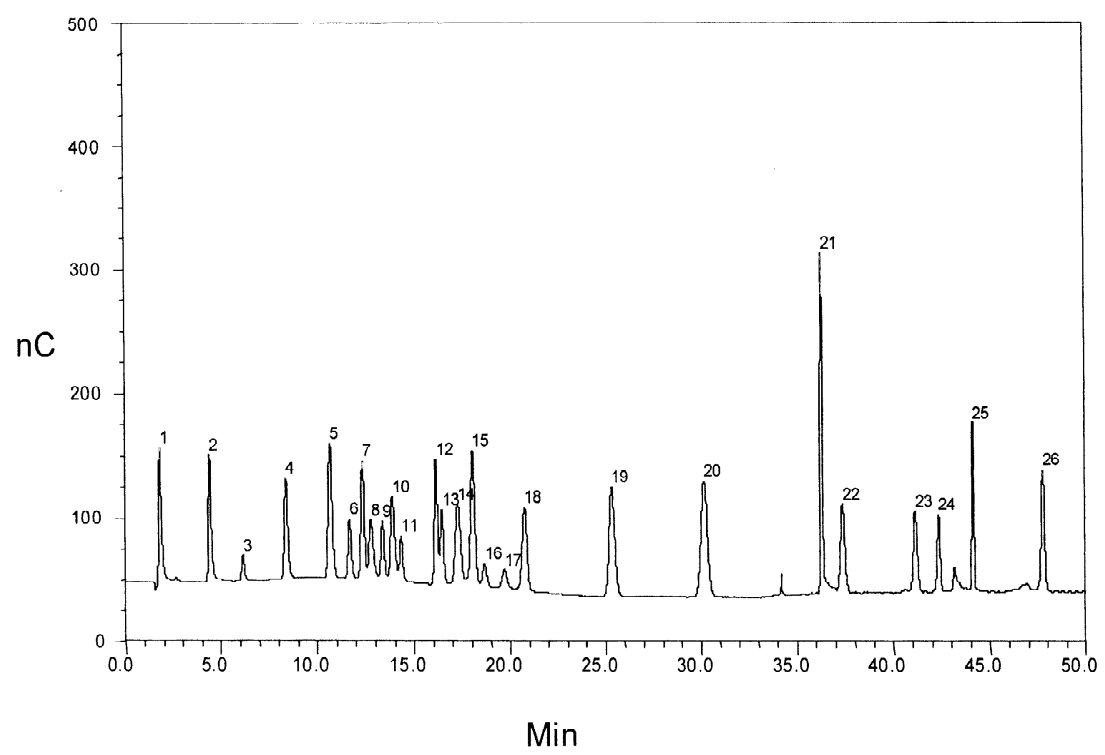

Fig. 3. Chromatogram of a standard mixture of 17 amino acids and nine carbohydrates. Chromatographic conditions: gradient method from Table 1; detection waveform from Table 2; flow rate $0.25 \mathrm{ml} / \mathrm{min}$; column temperature $30{ }^{\circ} \mathrm{C}$; injection volume $25 \mu \mathrm{l}$; AminoPac PA 10 column set. Peak: $1=$ arginine $(9.4) ; 2=$ fucose $(5.2) ; 3=$ lysine $(7.9) ; 4=$ arabinose $(4.5) ; 5=$ glucose $(5.8) ; 6=$ alanine $(8.0)$; $7=$ threonine (7.7); $8=$ fructose $(6.0) ; 9=$ glycine $(7.8) ; 10=$ ribose $(5.0) ; 11=$ valine $(7.8) ; 12=$ serine $(7.8) ; 13=$ proline $(7.8) ; 14=$ sucrose $(5.2) ;$ $15=$ lactose $(5.6) ; 16=$ isoleucine $(7.7) ; 17=$ leucine $(7.9) ; 18=$ methionine $(7.8) ; 19=$ raffinose $(6.3) ; 20=$ maltose $(11.3) ; 21=$ histidine (9.1); $22=$ phenylalanine (7.8); $23=$ glutamic acid (41.5); $24=$ aspartic acid (26.1); $25=$ cystine (3.7); 26=tyrosine (7.9). Values in bracket are the analyte concentrations $(\mu M)$.

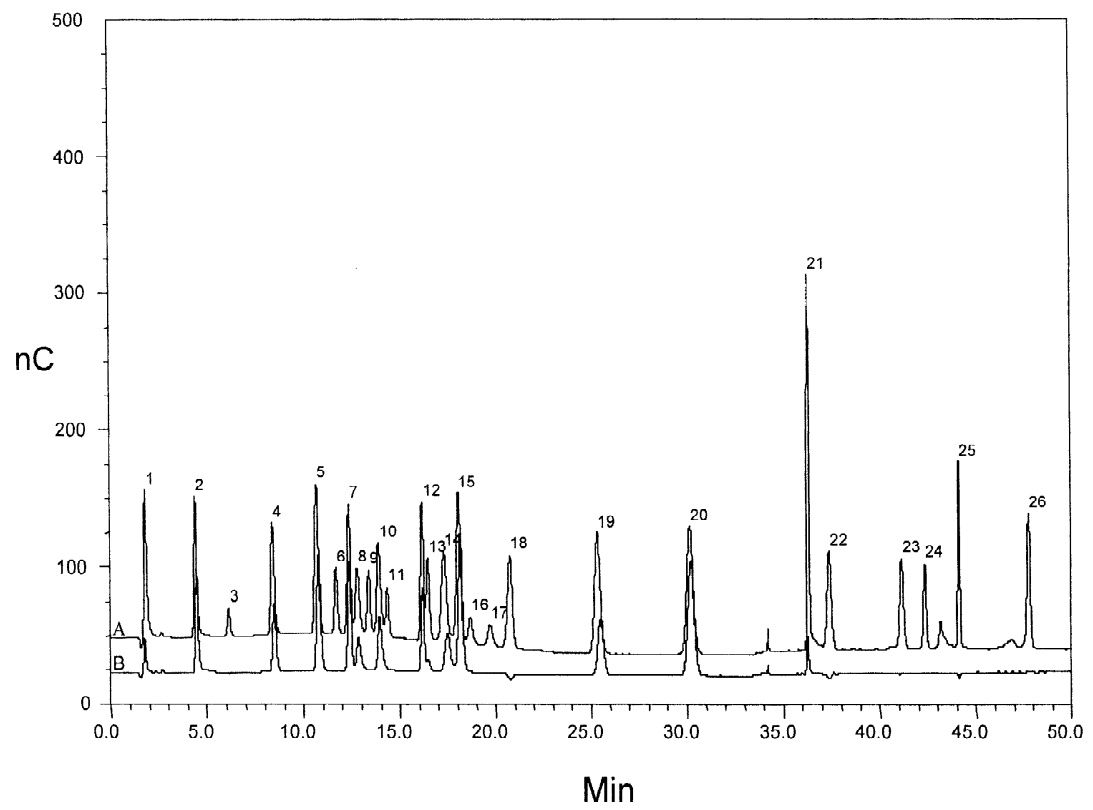

Fig. 4. Comparison of two detection waveforms for amino acids and carbohydrates. Chromatogram A: detection waveform from Table 2; chromatogram B: detection waveform from Table 4. Other chromatographic conditions, peak identities and the analyte amounts are given in Fig. 3. 
Table 3

Peak areas of amino acids and carbohydrates at different potentials ${ }^{\mathrm{a}}$

\begin{tabular}{|c|c|c|c|c|c|c|c|c|c|}
\hline \multirow[t]{2}{*}{ Analyte } & \multirow{2}{*}{$\begin{array}{l}\text { Quantity } \\
\text { (pmol) }\end{array}$} & \multicolumn{8}{|c|}{ Peak area $(\mathrm{nC} \min )$} \\
\hline & & $0.27 \mathrm{~V}$ & $0.22 \mathrm{~V}$ & $0.17 \mathrm{~V}$ & $0.12 \mathrm{~V}$ & $0.07 \mathrm{~V}$ & $0.02 \mathrm{~V}$ & $0.00 \mathrm{~V}$ & $-0.03 \mathrm{~V}$ \\
\hline Arginine & 235.0 & 16.23 & 9.60 & 4.96 & 4.21 & 3.87 & 3.18 & 3.28 & 2.98 \\
\hline Fucose & 128.8 & 16.88 & 16.72 & 16.08 & 15.44 & 14.40 & 13.33 & 11.57 & 10.01 \\
\hline Lysine & 197.6 & 3.32 & 1.42 & 0.11 & & & & & \\
\hline Arabinose & 112.3 & 16.85 & 16.39 & 15.37 & 13.93 & 12.96 & 11.71 & 10.19 & 9.99 \\
\hline Glucose & 145.0 & 25.47 & 24.89 & 24.47 & 23.53 & 22.76 & 20.88 & 19.89 & 19.57 \\
\hline Alanine & 200.8 & 9.23 & 5.00 & 0.71 & & & & & \\
\hline Threonine & 191.2 & 18.83 & 19.84 & 20.73 & 19.08 & 18.87 & 17.90 & 15.86 & 15.81 \\
\hline Fructose & 149.8 & 11.68 & 10.77 & 10.21 & 9.09 & 8.04 & 6.67 & 6.09 & 6.05 \\
\hline Glycine & 196.0 & 7.90 & 3.95 & 0.33 & & & & & \\
\hline Ribose & 125.8 & 15.65 & 15.10 & 14.89 & 13.94 & 12.27 & 10.88 & 9.74 & 9.71 \\
\hline Valine & 195.2 & 6.66 & 4.23 & 0.83 & & & & & \\
\hline Serine & 194.4 & 18.59 & 17.32 & 14.66 & 13.58 & 13.25 & 12.83 & 11.42 & 10.95 \\
\hline Proline & 195.2 & 12.51 & 12.09 & 10.61 & 7.52 & 5.14 & 3.12 & 1.83 & \\
\hline Sucrose & 129.3 & 19.16 & 20.07 & 18.91 & 16.89 & 14.87 & 12.51 & 9.59 & 8.72 \\
\hline Lactose & 141.0 & 33.58 & 34.49 & 33.13 & 31.63 & 31.96 & 30.87 & 28.95 & 27.72 \\
\hline Isoleucine & 191.2 & 4.45 & 3.77 & 1.46 & & & & & \\
\hline Leucine & 198.4 & 4.52 & 4.05 & 1.65 & 0.12 & & & & \\
\hline Methionine & 194.4 & 19.38 & 12.29 & 3.02 & & & & & \\
\hline Raffinose & 158.0 & 30.97 & 29.04 & 26.01 & 23.42 & 20.62 & 17.67 & 13.95 & 13.90 \\
\hline Maltose & 282.5 & 38.87 & 40.90 & 39.71 & 37.15 & 37.01 & 36.36 & 34.10 & 33.83 \\
\hline Histidine & 226.4 & 37.02 & 25.80 & 17.01 & 10.47 & 6.58 & 4.48 & 3.32 & 3.23 \\
\hline Phenylalanine & 195.2 & 18.28 & 15.85 & 9.23 & 2.81 & & & & \\
\hline Glutamic acid & 1037.5 & 14.60 & 10.27 & 2.95 & 0.26 & & & & \\
\hline Aspartic acid & 652.5 & 10.97 & 8.53 & 3.04 & 0.25 & & & & \\
\hline Cystine & 92.8 & 16.60 & 15.81 & 11.10 & 4.21 & 0.30 & & & \\
\hline Tyrosine & 197.6 & 19.42 & 16.99 & 12.42 & 4.20 & 0.43 & & & \\
\hline
\end{tabular}

\footnotetext{
${ }^{\text {a }}$ Gradient condition is from Table 1 .
}

acids do not decrease at all or decrease only slightly with the decreasing sampling step potential. When the sampling step potential becomes less than $0.12 \mathrm{~V}$,

Table 4

Detection waveform for carbohydrates and hydroxyl amino acids

\begin{tabular}{rcl}
\hline $\begin{array}{l}\text { Time } \\
(\mathrm{ms})\end{array}$ & $\begin{array}{l}\text { Potential }(\mathrm{V}) \\
\text { vs. } \mathrm{Ag} / \mathrm{AgCl}(3 \mathrm{M} \mathrm{KCl})\end{array}$ & $\begin{array}{l}\text { Current } \\
\text { integration }\end{array}$ \\
\hline 0 & -0.20 & \\
40 & -0.20 & \\
50 & 0.00 & Begin \\
210 & 0.00 & \\
220 & 0.00 & \\
460 & 0.00 & \\
470 & 0.00 & \\
560 & 0.00 & \\
570 & -2.00 & \\
580 & -2.00 & \\
590 & 0.60 & \\
600 & -0.20 & \\
\hline
\end{tabular}

some amino acids cannot be detected at all. This type of change, which is instantaneous and reversible (in contrast to the passivation discussed in the preceding paragraph which is gradual and difficult to reverse except by polishing), indicates that the required potential of detection is higher for non-hydroxyl amino acids than for carbohydrates and hydroxyl amino acids.

One of the consequences of the different detection potential requirements is that carbohydrates and hydroxyl amino acids can be distinguished from amino acids not carrying hydroxyl by using a different value for the sampling step potential. The waveform for simultaneous detection of amino acids and carbohydrates is given in Table 2. The waveform for selective detection of carbohydrates and hydroxyl amino acids is presented in Table 4. Fig. 4 shows the chromatograms obtained with the two different waveforms. From Fig. 4, we can see that the peaks 
of all amino acids were observed together with carbohydrates using the detection waveform from Table 2. However, when the detection waveform from Table 4 was employed, the detection became more selective. The peaks of carbohydrates and hydroxyl amino acids were still observed, but the peaks of non-hydroxyl amino acids either disappeared or were much reduced in size. A method employing the two different detection waveforms can thus be useful for identifying amino acids and carbohydrates in an unknown sample.

\subsection{Reproducibility, detection limit and linearity of method}

The RSD (relative standard deviation), detection limit and linear range of calibration for amino acids and carbohydrates, measured under gradient conditions of Table 1 , detection waveform of Table 2 and injection volume of $25 \mu$, are given in Table 5 . The RSD values of peak areas were determined by making five repetitive injections of amino acids and carbohydrates. The detection limits were calculated as three times the signal (peak height)-to-noise ratios. The calibration graphs using peak areas were linear for all the analytes over three orders of magnitude. All correlation coefficients were in the range of $0.9950-0.9999$. Experimentally, we also have verified that the reproducibility and detection limit remained unchanged. The signal and noise decrease going from the waveform of Table 2 to the waveform of Table 4 . The correlation coefficients of calibration plots are all in the range of 0.9950 0.9999 .

\subsection{Sample analysis and recovery}

The method of selective waveforms, discussed in

Table 5

Reproducibility, detection limit and linearity of method

\begin{tabular}{|c|c|c|c|c|c|}
\hline Analyte & $\begin{array}{l}\mathrm{RSD} \\
(\%) \\
(n=5)\end{array}$ & $\begin{array}{l}\text { Detection limit } \\
(\mathrm{n} M) \\
(S / N=3)\end{array}$ & $\begin{array}{l}\text { Regression equation, } \\
y=\text { peak area }(\mathrm{nC} \min ), \\
x=\text { concentration }(\mu M)\end{array}$ & $\begin{array}{l}\text { Correlation } \\
\text { coefficient } \\
(n=5)\end{array}$ & $\begin{array}{l}\text { Linear } \\
\text { range } \\
(\mu M)\end{array}$ \\
\hline Arginine & 3.1 & 20.8 & $y=1.13 x+0.47$ & 0.9978 & $0.5-20$ \\
\hline Fucose & 1.3 & 9.9 & $y=3.22 x+0.51$ & 0.9986 & $0.2-100$ \\
\hline Lysine & 2.0 & 112.9 & $y=0.25 x+0.46$ & 0.9981 & $0.5-100$ \\
\hline Arabinose & 1.2 & 10.8 & $y=2.88 x+0.56$ & 0.9985 & $0.2-100$ \\
\hline Glucose & 1.4 & 10.2 & $y=4.14 x+1.09$ & 0.9971 & $0.2-100$ \\
\hline Alanine & 1.4 & 39.3 & $y=0.92 x+0.50$ & 0.9991 & $0.5-50$ \\
\hline Threonine & 1.2 & 16.2 & $y=2.23 x+0.59$ & 0.9999 & $0.2-50$ \\
\hline Fructose & 1.5 & 23.4 & $y=1.97 x+0.45$ & 0.9996 & $0.2-100$ \\
\hline Glycine & 3.0 & 37.1 & $y=0.87 x+0.66$ & 0.9997 & $0.5-50$ \\
\hline Ribose & 1.2 & 13.0 & $y=3.12 x+0.77$ & 0.9998 & $0.2-100$ \\
\hline Valine & 1.6 & 49.5 & $y=0.58 x+0.42$ & 0.9951 & $0.5-50$ \\
\hline Serine & 1.3 & 14.9 & $y=2.49 x-0.39$ & 0.9966 & $0.2-50$ \\
\hline Proline & 2.3 & 29.6 & $y=1.13 x+0.40$ & 0.9989 & $0.5-50$ \\
\hline Sucrose & 2.0 & 16.5 & $y=3.37 x+0.96$ & 0.9993 & $0.5-100$ \\
\hline Lacrose & 1.8 & 9.0 & $y=5.34 x+0.45$ & 0.9999 & $0.5-100$ \\
\hline Isoleucine & 2.8 & 83.7 & $y=0.55 x+0.71$ & 0.9995 & $0.5-100$ \\
\hline Leucine & 2.9 & 105.9 & $y=0.52 x+0.48$ & 0.9999 & $0.5-100$ \\
\hline Methionine & 1.8 & 25.7 & $y=1.73 x+0.60$ & 0.9977 & $0.2-50$ \\
\hline Raffinose & 1.8 & 15.2 & $y=4.25 x+0.56$ & 0.9995 & $0.5-100$ \\
\hline Maltose & 1.8 & 23.2 & $y=3.21 x-0.05$ & 0.9999 & $1.0-200$ \\
\hline Histidine & 3.3 & 7.3 & $y=3.18 x+0.55$ & 0.9973 & $0.2-20$ \\
\hline Phenylalanine & 1.2 & 25.4 & $y=1.85 x+0.31$ & 0.9987 & $0.5-50$ \\
\hline Glutamic acid & 3.1 & 207.1 & $y=0.18 x-0.59$ & 0.9954 & $2.0-150$ \\
\hline Aspartic acid & 1.7 & 107.1 & $y=0.27 x+0.82$ & 0.9984 & $0.5-100$ \\
\hline Cystine & 1.6 & 5.2 & $y=3.47 x+0.47$ & 0.9950 & $0.5-50$ \\
\hline Tyrosine & 2.3 & 16.8 & $y=1.67 x+0.49$ & 0.9991 & $0.5-50$ \\
\hline
\end{tabular}


Table 6

The results of analysis for amino acids and carbohydrates in a liquid condiment sample

\begin{tabular}{|c|c|c|c|}
\hline Component & $\begin{array}{l}\text { Detected level in the } \\
\text { sample diluted } 500 \text {-fold }(\mu M)\end{array}$ & $\begin{array}{l}\text { Detected level } \\
\text { in the sample }(\mathrm{mg} / \mathrm{l})\end{array}$ & $\begin{array}{l}\mathrm{RSD} \\
(\%)\end{array}$ \\
\hline Lysine & 1.7 & 124 & 4.5 \\
\hline Alanine & 6.5 & 290 & 2.6 \\
\hline Threonine & 1.7 & 101 & 2.5 \\
\hline Glycine & 1.8 & 68 & 4.7 \\
\hline Valine & 2.8 & 164 & 2.9 \\
\hline Serine & 1.9 & 100 & 2.7 \\
\hline Proline & 1.7 & 98 & 2.3 \\
\hline Isoleucine & 2.1 & 138 & 3.2 \\
\hline Leucine & 3.3 & 216 & 4.0 \\
\hline Methionine & 0.3 & 22 & 3.2 \\
\hline Histidine & 0.4 & 31 & 5.1 \\
\hline Phenylalanine & 1.2 & 99 & 3.1 \\
\hline Glutamic acid & $45.0^{\mathrm{a}}$ & 66208 & 4.0 \\
\hline Aspartic acid & 3.4 & 226 & 3.1 \\
\hline Cystine & 1.1 & 132 & 4.1 \\
\hline Tyrosine & 0.9 & 82 & 3.1 \\
\hline Glucose & 3.6 & 324 & 2.2 \\
\hline Fructose & 0.4 & 36 & 2.6 \\
\hline Sucrose & 2.1 & 359 & 2.5 \\
\hline Maltose & 1.2 & 205 & 3.1 \\
\hline
\end{tabular}

All data are average values from five independent measurements.

${ }^{a}$ Detected level in the sample diluted 10000 -fold.

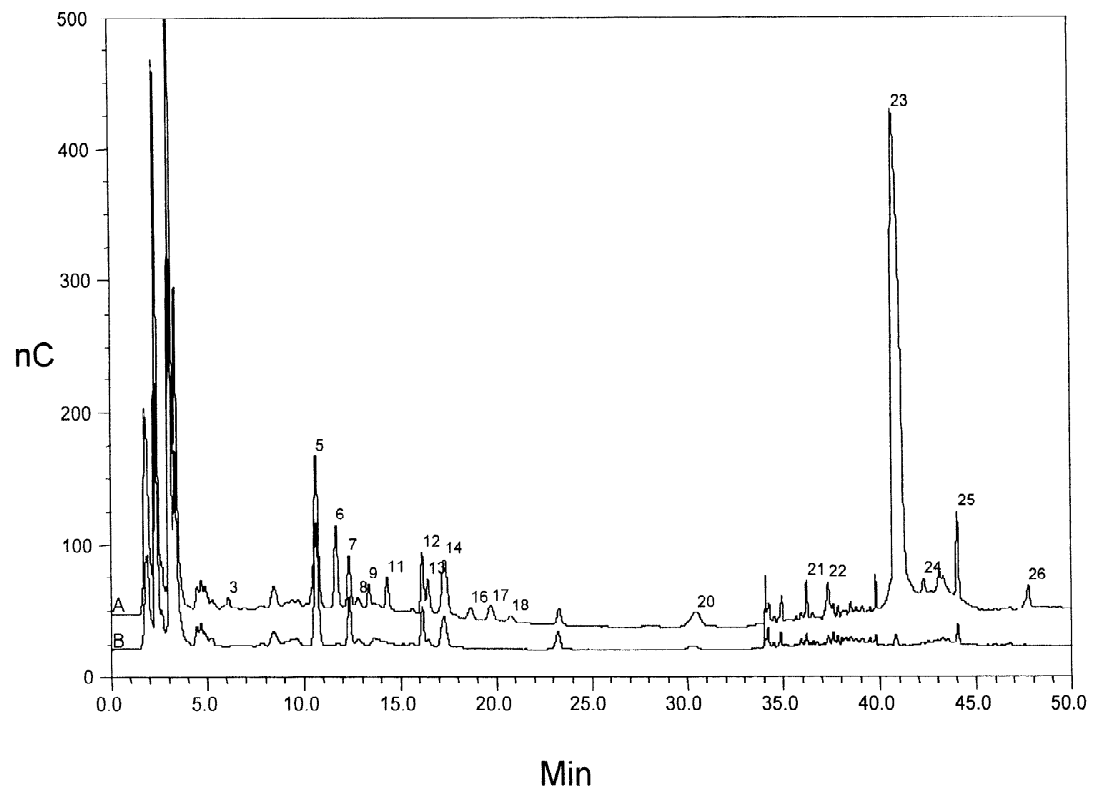

Fig. 5. Chromatograms of a liquid condiment solution diluted 500-fold. Chromatogram A: detection waveform from Table 2; chromatogram B: detection waveform from Table 4. Other chromatographic conditions and peak identities are given in Fig. 3. The analyte amounts are shown in Table 6. 
Table 7

Results for determination of recovery with the proposed method

\begin{tabular}{lcccc}
\hline Component & $\begin{array}{l}\text { Amount } \\
\text { added }(\mu M)\end{array}$ & $\begin{array}{l}\text { Amount found } \\
(\mu M)\end{array}$ & $\begin{array}{l}\text { Recovery } \\
(\%)\end{array}$ & $\begin{array}{l}\text { RSD } \\
(\%)\end{array}$ \\
\hline Lysine & 1.98 & 1.75 & 88.4 & 4.7 \\
Alanine & 2.00 & 1.85 & 92.5 & 3.1 \\
Threonine & 1.92 & 1.84 & 95.8 & 2.8 \\
Glycine & 1.95 & 1.82 & 93.3 & 4.0 \\
Valine & 1.95 & 1.90 & 97.4 & 3.0 \\
Serine & 1.95 & 1.88 & 96.4 & 3.0 \\
Proline & 1.95 & 1.83 & 93.8 & 2.0 \\
Isoleucine & 1.92 & 1.78 & 92.7 & 3.0 \\
Leucine & 1.98 & 2.00 & 101.0 & 4.2 \\
Methionine & 1.95 & 1.96 & 100.5 & 2.9 \\
Histidine & 2.28 & 2.09 & 91.7 & 5.8 \\
Phenylalanine & 1.95 & 1.77 & 90.8 & 2.9 \\
Glutamic acid & 20.8 & 18.6 & 89.4 & 4.4 \\
Aspartic acid & 6.52 & 6.02 & 92.3 & 3.3 \\
Cystine & 0.92 & 0.82 & 89.1 & 5.4 \\
Tyrosine & 1.98 & 1.88 & 94.9 & 3.7 \\
Glucose & 1.45 & 1.39 & 95.9 & 2.7 \\
Fructose & 1.50 & 1.40 & 93.3 & 3.1 \\
Sucrose & 1.30 & 1.23 & 94.6 & 2.8 \\
Maltose & 2.82 & 2.66 & 94.3 & 3.3 \\
\hline
\end{tabular}

All data are average values from five independent measurements.

the preceding paragraph, was used for the simultaneous determination of amino acids and carbohydrates in a liquid condiment without any sample pre-treatment. Samples were diluted 500 -fold for determining all components except for glutamic acid, and 10000 -fold for determining glutamic acid, with $18 \mathrm{M} \Omega$ water and filtered through a $0.45-\mu \mathrm{m}$ membrane filter prior to injection. The diluted samples were analyzed under the chromatographic conditions in the Experimental section. The chromatograms of a liquid condiment sample diluted 500-fold are shown in Fig. 5. We identified some of the peaks, including 16 amino acids and four carbohydrates in the chromatograms, by spiking with known standards and employing the two different detection waveforms from Tables 2 and 4 for each of the samples. The peak area calibration graphs were used for quantitative determinations. Recovery experiments were performed by adding known amounts of amino acids and carbohydrates to the sample. Tables 6 and 7 summarize the analytical results and recoveries of identified components in the analyzed sample, respectively. The results demonstrate both high accuracy and good precision of the new method.

\section{Conclusions}

A chromatographic method has been developed for direct, simultaneous determination of amino acids and carbohydrates in a single run by anion-exchange chromatography followed by integrated pulsed amperometric detection. There are differences in retention behavior between amino acids and carbohydrates. These differences can be used for improving separations of amino acids and carbohydrates. Separation of 17 amino acids and nine carbohydrates was developed. Carbohydrates and hydroxyl amino acids can be detected selectively by choosing a modified detection waveform. Application of two different waveforms to the same sample can be used to determine whether an unknown peak is a non-hydroxyl amino acid or a carbohydrate and a hydroxyl amino acid. As an application example, we show simultaneous determination of 16 amino acids and four carbohydrates in a liquid condiment. There is no need for sample pre-treatment. The reported method is simple, sensitive, reliable and easy to operate. We believe that the method can be applied to a variety of other samples.

\section{References}

[1] D.H. Spackman, W.H. Stein, S. Moore, Anal. Chem. 30 (1958) 1190.

[2] K.L. Woo, in: C. Cooper, N. Packer, K. Williams (Eds.), Amino Acid Analysis Protocols, Methods in Molecular Biology, Vol. 159, Humana Press, Totowa, NJ, 2001, p. 141.

[3] J.T. Smith, Electrophoresis 20 (1999) 3078.

[4] A. Fox, J. Chromatogr. A 843 (1999) 287.

[5] Z. El Rassi, J. Chromatogr. A 720 (1996) 93.

[6] Y.C. Lee, J. Chromatogr. A 720 (1996) 137.

[7] Z. El Rassi, Electrophoresis 20 (1999) 3134.

[8] A.P. Clarke, P. Jandik, R.D. Rocklin, Y. Liu, N. Avdalovic, Anal. Chem. 71 (1999) 2774.

[9] P. Jandik, J. Cheng, D. Jensen, S. Manz, N. Avdalovic, J. Chromatogr. B 758 (2001) 189.

[10] P. Jandik, J. Cheng, D. Jensen, S. Manz, N. Avdalovic, Anal. Biochem. 287 (2000) 38.

[11] P. Jandik, A.P. Clarke, N. Avdalovic, D.C. Andersen, J. Cacia, J. Chromatogr. B 732 (1999) 193.

[12] L.E. Welch, W.R. LaCourse, D.A. Mead Jr., D.C. Johnson, T. Hu, Anal. Chem. 61 (1989) 555. 